for discussion by Mr. Standing, and also incline me to suggest a modification of my previously expressed views.

The evidence afforded by the cranial casts is very precise and unmistakable. One of them does not differ in any essential feature, excepting size, from the form exhibited by the brain in the living species of the genus Lemur; a second is an almost exact replica of the cranial cast of Indris; and the third, so far from affording any evidence of affinity to monkeys, presents highly specialised features, which enable us to place the animal (and also Nesopithecus, Megaladapis, and possibly Chiromys) within the fringe of the Indrisinæ. As these lemuroids are the most' diversely modiked members of the most highly specialised family of the Prosimia-which means that they are furthest removed from (and presumably have retained least .resemblance to) the very early and remote ancestor from which both lemurs and apes could have sprung-it follows that these, the most aberrant and outlying branches of the prosimian phylum, are the least likely to supply us with any evidence bearing on the relationship of lemurs to apes; and the facts elucidated by the actual examination of these specimens quite bear out this a priori supposition.

I am the more anxious to make my position absolutely clear in regard to this matter for the reason that, some four years ago (Linn. Soc. Journal-Zool., vol. xxix., p. $\left.8_{3}\right)$, in protesting against Hubrecht's suggested exclusion of all Prosimia (except 'Tarsius) from the Primates, I may: have unduly minimised the differences in structure that indicate the wide separation of the Lemuroidea and the Anthropoidea.

The organisation of every part of the body proclaims the kinship of lemurs and monkeys, distant though it be; this has been so often summarised (see Earle, "On the Affinities of Tarsius," the American Naturalist, 1897, pp. 569 and 680) that it does not need repetition. I might direct attention to the fact that the lemurs are the only mammals that exhibit the true Sylvian fissure such as we find in the Anthropoidea or Simiæ; that the true central (Rolando's) sulcus is present in Perodicticus and in no non-Primate mammal, although there are distinct evidences in many prosimian families of the tendency toward the development of this caudal-limiting sulcus of the motor area; that the motor area presents histological features like those of the lowlier monkeys, and has a similar topographical distribution; that the calcarine sulcus and the distribution of the visual cortex (area striata) conform essentially to the Primate type, although in certain respects the structure of this cortex and its relation to sulci more nearly resembles the condition found in certain primitive Carnivora; and that the organisation of the other parts of the cerebral hemisphere and of the brain-stem and cerebellum resembles that of the corresponding parts of the brain in monkeys much more nearly than that of the Carnivora and Edentata, in which there are some analogies to the Prosimiæ.

But if the facts of cerebral anatomy establish the claim of the Prosimiæ to be included in the Primates, they afford equally emphatic evidence of the sharp line of demarcation between the diversely specialised suborders Lemuroidea (Lemures) and Anthropoidea (Simiæ) and the degraded rank of the former. In attempting to formulate the contrasts between these two suborders, Tarsius comes to occupy such an enigmatical position that it must be put into a category by itself, the suborder Tarsii (Gadow), the other Lemuroidea then forming the suborder Lemures (Hubrecht).

The Lemures are macrosmatic, and (excluding Megaladapis) have a sessile olfactory bulb, whereas the Simix are microsmatic, and have an elongated olfactory peduncle. Tarsius has a sessile olfactory bulb like the Lemures, and in form exactly like that of the Galaginæe and Lorisinæ, but it is much smaller than that of any lemur, and at the same time is bigger than that of a monkey.

The cerebral hemisphere in the Simiæ is prolonged backward to cover the cerebellum, carrying with it a diverticulum of the lateral ventricle to form a posterior cornu, the walls of which are composed to a large extent of very highly specialised striate cortex differing markedly in structure from the homologous area of other mammalian orders. In Lemures the occipital prolongation is not so extensive; there is no posterior cornu, and the cortex of the area striata approximates in structure to that of the Carnivora more nearly than to that of the apes. In Tarsius the extent of the occipital pole and its form most ntarly resemble the condition found in the brain of the Galaginæ, but there is an extensive posterior cornu as in the apes, and the structure of the area striata presents a marked contrast to that of the lemurs, and resembles that found in Hapale and Cebus.

In the lemurs the frontal, temporal, and parietal association areas are much smaller than in monkeys.

The lateral hemispheres of the cerebellum exhibit a much greater expansion in the Simiæ than in the Lemures, although there is a very close resemblance between the patterns exposed in mesial section in the two suborders.

In many respects the structure of the brain in Tarsius departs widely from that of all the other Primates, both Lemures and Simix. Most of these features, such as the form and proportions of the corpus callosum and the architecture of the cerebellum, are indicative of a very primitive generalised condition, such as we find in the insectivore Gymnura.

All these considerations, and the mass of facts elucidated by Burmeister, Turner, Hubrecht, Mivart, Leche, Eugen Fischer, and the writer among many others, can, I think, find a rational explanation only by admitting that the Primates consist of three divergent phyla, which have all departed in varying degrees and in different ways from their original common ancestor, which must have been a creature in many respects like Thrsius, but more macrosmatic, and possessed of a smaller and less highly specialised visual cortex.

The School of Medicine, Cairo, April 22.

\section{Radium and Geology}

Iwo points of special interest have come to light in recent investigations which $I$ have made in connection with this subject.

(I) Typical rocks from the Simplon Tunnel contain quantities of radium considerably in excess of the average of igneous rocks. The Simplon rocks are altered sediments, for the most part, from Archæan to Jura-Lias age. There appears to be sufficient radium to account for the excessive temperatures met with in boring the tunnel, and the practical suggestion is allowable that engineers will do well to estimate the distribution of this substance before embarking on similar projects in the future.

The investigation suggests that radium, accumulating in great thicknesses of sedimentary deposits, may enter as a factor in mountain building by raising the temperature at the base of the accumulated mass. This would lead to a lessened resistance to compressive stress and pressure from beneath. In short, it will be for future investigation to explore how far radium (and uranium) in the surface materials has proved a source of instability in geological history, its transport by denudation being, in fact, not a transport of matter only, but a convection of energy.

(2) A sample of red clay from a depth of 2740 fathoms in the North Atlantic contained sixteen times as much radium as the average of igneous rocks as determined by the Hon. R. J. Strutt, and a specimen of globigerina ooze from a depth of rggo fathoms in the South Atlantic about six times this average. These materials I owe to the kindness of Sir John Murray.

Here the question will arise, Whence all this radium? Sir John Murray's cosmic dust, of course, at once comes to mind, and, taking all the facts into account, I venture to regard these results as further evidence in favour of the extra-terrestrial origin of some portion of the radium we find upon the earth.

The above results are obtained by measurement of the emanation, with every precaution against error.

The point as to what constituent of the oceanic deposits is responsible for the radium is under investigation.

Geological Laboratory, Trinity College, Dublin, J. JoLY. 